
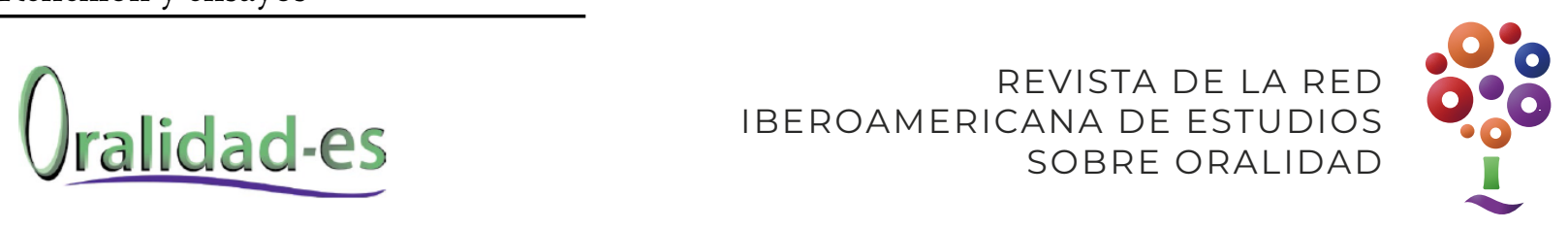

\title{
El discurso del cómic de superhéroes y las Relaciones Internacionales
}

\section{The discourse of the superhero comics and International Relations}

\author{
Geisy Bertel \\ geisybertel13@gmail.com \\ Universidad de La Salle, Colombia \\ Camila Alejandra Casagua-Guerrero \\ ccasagua36@unisalle.edu.co \\ Universidad de La Salle, Colombia
}

Bertel, G. \& Casagua-Guerrero, C. A. (2020). El discurso del cómic de superhéroes y las Relaciones Internacionales. Oralidad-es, 6, 1-17. https://revistaoralidad-es.com/index.php/ro-es/article/view/126/132

Fecha de recepción: 14 de octubre de 2020 / Fecha de aceptación: 28 de diciembre de 2020 


\section{Resumen}

Los cómics son historias narradas por medio de viñetas, mediante las cuales pueden transmitir ciertos tipos de valores culturales, discursos, sentimientos, emociones e ideologías. En el siguiente artículo se evidencia cómo los cómics de superhéroes, a lo largo de los años, han servido como instrumentos para articular distintos tipos de discursos en función de los intereses de ciertos países. Teóricamente esta estrategia se conoce como diplomacia cultural, la cual permite que se exporten diferentes ideas por medio de productos culturales, que pueden incentivar discursos nacionalistas en todo el mundo. En este sentido, se presenta la relación que existe entre la trama de las historietas y los contextos históricos en la dimensión de las relaciones internacionales para descubrir cómo el discurso del cómic de superhéroes es utilizado como instrumento de maniobra política en las relaciones internacionales.

\section{Palabras Clave}

Diplomacia cultural; Historia Estelar; semiótica; nacionalismo; superhéroes; cómics; discurso

\section{Abstract}

Comics are stories told through a couple of vignettes through which certain types of cultural values, discourses, feelings, emotions, and ideologies can be transmitted. In the following article, it will be evident how the superhero comics over the years have served as instruments to articulate different types of discourses depending on the interests of certain countries. Theoretically this strategy is known as cultural diplomacy, thus allowing different ideas to be exported through cultural products, which can incentivize nationalist discourses around the world. This article will show the relationship that exists between the plot of comics and historical contexts in the dimension of international relations to discover, how is the discourse of superhero comics used as an instrument of political maneuvering in international relations?

Keywords

Cultural diplomacy; Stellar History; semiotics;

nationalism; superheroes, comics; discourse 


\section{Introducción}

Los cómics de superhéroes, en su capacidad para articular un discurso y generar significado, poseen un grado de complejidad potencial equivalente al de cualquier otro producto cultural, que va mucho más allá de la simple construcción de una mitología. Como consecuencia, las relaciones entre poder, violencia y orden social han estado siempre presentes en el inconsciente de sus lectores y en la reflexión de muchos autores, sometidas con frecuencia a sutiles valoraciones políticas (Hernández-Cano, 2009). Reconociendo lo anterior, este artículo enfatiza en el análisis del discurso de las narrativas que se utilizan en los cómics como discursos de las Relaciones Internacionales.

En este sentido, el objetivo general de la investigación de la cual se deriva el artículo fue identificar por qué Estados Unidos utilizaba los cómics de superhéroes como instrumento de maniobra política en las relaciones internacionales. Los objetivos específicos que guiaron la investigación fueron: 1) identificar elementos políticos propios de las teorías y los conceptos de las Relaciones Internacionales en las narrativas de los cómics de superhéroes e 2) identificar la causalidad entre la creación de los cómics y los hitos más importantes del contexto histórico mundial.

En este artículo se evidencia la capacidad que tienen los comics, considerados como un objeto cultural, para influenciar a cierto público, al utilizar tramas narrativas para cautivar al espectador y demostrar cierta realidad virtual o ficcionada, muy cercana a la complejidad de las Relaciones Internacionales. Este interés se enfoca en la diplomacia cultural, constructo de las Relaciones Internacionales en el ámbito del Soft Power (Saddiki, 2009; Rodríguez-Barba, 2015) que evidencia la influencia cultural a partir de algunos de los discursos utilizados.
La noción de poder blando o Soft Power ha sido desarrollads por Joseph S. Nye (1990). Para este autor el cine y la televisión americanos ayudan a difundir globalmente ideas asociadas a la cultura estadounidense, como la libertad, el individualismo y la capacidad de cambio. Entonces, por medio de la cultura popular se muestra la identidad de un país, sus valores, sus logros y, entonces, se persuade a otros de querer ser como ellos. Cuando el resto del mundo desea ser como otro, admira sus valores y acepta sus credos, entonces, "se realza nuestro poder blando, es decir, nuestro reclamo cultural e ideológico” (Sánchez-Román, 2015, p. 24).

Es importante resaltar que, previo a la creación de este artículo, se realizó una revisión de literatura, en la cual que se identificó la existencia de diversos documentos que aportan conceptualmente sobre cada uno de los temas por separado. Sin embargo, no se hallaron documentos que relacionaran los cómics con las Relaciones Internacionales. Por consiguiente, este artículo pretende tener un alcance exploratorio al respecto.

Para la revisión bibliográfica del tema se realizó a partir de diferentes bases de datos, tales como EBSCO, Jstor, Dialnet, entre otras y, también, se consideró información publicada en blogs escritos por conocedores del tema de la cultura geek. Adicionalmente, se retomaron los planteamientos de autores como Joseph Nye (1990), Hans Morgenthau (1975) y Karl Deutsch (1988), que brindaban una base teórica de aproximaciones conceptuales sobre la diplomacia cultural y como se relaciona con el poder blando.

La elección de los cómics para esta investigación se realizó teniendo en cuenta el contexto y lo que se buscaba representar en el momento de su creación. Es decir, la relevancia de la semiótica de los cómics y los vestuarios de los personajes. Del mismo modo se analizaron los valores y las fechas de la creación de estos cómics para filtrar cuáles se podían relacionar con las Relaciones 
Internacionales y sus teorías. Finalmente, se tuvieron en cuenta, principalmente, aquellos que fueron creados durante la II Guerra Mundial o durante algún conflicto internacional, en el cual estaba involucrado Estados Unidos (por ejemplo, el conflicto de Vietnam).

Adicionalmente, es importante destacar que un concepto clave de la investigación fue la historia Estelar, la cual se basa en que

Los acontecimientos en una narración tienen una constelación de sentido en la historia, asi como existe una cantidad innumerable de estrellas, también hay acontecimientos que en la suma de ellos no tienen sentido y pueden ser innumerables, pero el oficio del historiador, así como el del astrónomo, está en identificar patrones narrativos a partir de los hechos o estrellas más relucientes. $Y$ desde alli se establecen descripciones que reconstruyen significados narrativos del pasado. Así que, el pasado puede ser una gran bóveda celeste esperando a ser interpretada para formar una constelación de sentido. Esta constelación de sentido es construida por el historiador desde su entorno cultural, desde la creación de una trama que le adjudica a cada acontecimiento un tipo especial de significado. (Ojeda-Pérez y Zapata, 2018, p. 532)

La creación de los cómics de superhéroes puede clasificarse, según McCue y Bloom (1993 citado en Hernández-Cano, 2009), en una serie de épocas: edad de oro, de plata y moderna. Además, Hernández-Cano (2009) brinda un contexto en el cual se pueden identificar de manera más clara las diferentes etapas por las que ha pasado el cómic, junto con los cambios sufridos y de qué forma estos han sido utilizados como medio para expandir discursos políticos o simbólicos. Para este trabajo se relacionarán las etapas mencionadas con el momento histórico en el que nació cada cómic analizado, para, así, hallar la conexión entre las Relaciones Internacionales y el estudio narrativo de los mismos. Como consecuencia, será posible evidenciar que el contexto histórico se vincula con algunos tiempos determinados, en los cuales fueron creados los superhéroes y cuáles fueron las posibles intenciones de su creación.

En cuanto a la historia de algunos personajes influyentes en el mundo del cómic, se menciona autores como Castañeda-Lozano (2018), cuyos planteamientos permitieron el análisis de aquellas características e identificar cómo las personas adquierían algunas de estas sin darse cuenta. Adicionalmente, Corrales (2014) brinda soporte a un panorama que permitió contemplar algunos superhéroes contemporáneos que demostraron que el legado de la utilización de armas en este tipo de tramas continuaba siendo una de las cualidades principales en la industria.

Por otro lado, a lo largo de la historia Estados Unidos siempre se ha buscado incentivar y fomentar, tanto en sus ciudadanos como en todo el mundo, un sentimiento nacionalista. Para ello, descubrieron en el cómic y en la imagen que este transmitía una forma más sencilla de llegar a los ciudadanos (Bernasconi y Salgueiro, s.f.). Sin embargo, fue a finales de los años noventa cuando el discurso del cómic empezó a convertirse en un tipo de narrativa más simbólica sobre el poder del mundo contemporáneo. De este modo, se alimentaron los diferentes escenarios políticos como, por ejemplo, el terrorismo, la polarización de la vida política americana y el desequilibrio del poder mundial, para, así, manipular la realidad a su favor (Hernández-Cano, 2009).

En relación con lo anterior, Del Rosario (2016) plantea cómo las imágenes y las representaciones creadas por el cómic podían ser usadas políticamente para transmitir un mensaje que favorecía intereses específicos. Además, superhéroes como el Capitán América o Superman sirvieron a manera de propaganda durante la Segunda Guerra Mundial y otros momentos históricos importantes como la Guerra Fría, entre otros. 
Por su parte, Rodríguez-Barba (2015) se enfocan en la manera en la que la industria del cómic ha logrado tener gran influencia en la opinión pública durante, también, las épocas de la Gran Depresión, la Segunda Guerra Mundial y la Guerra de Vietnam. Esto, principalmente, por medio de ejemplares como Superman, quien desde sus inicios fue utilizado como propaganda durante la Segunda Guerra Mundial y la Guerra fría.

Por otra parte, Cuñarro y Finol (2013) plantean cómo la semiótica es un elemento que, también, permite estudiar el uso del cómic para transmitir un mensaje específico, a partir, por ejemplo, de darle significado a una imagen o con los símbolos que se constituyen en él.

Todo lo anterior se encuentra fuertemente relacionado con el Nacionalismo, el cual, según la Sociología en el cómic (2011), puede posicionar a una nación específica como un referente identitario a nivel mundial. En este sentido, es posible relacionar al Capitán América y a Superman con dicho concepto.

Al respecto, Sánchez-Román (2015) y Botello (s.f.) plantean cómo los eventos del 11 de septiembre crearon un nuevo escenario mundial, en el cual el gobierno de los Estados Unidos encontró en la industria cinematográfica la estrategia de poder blando para articular un discurso que les permitiera justificar muchas de sus acciones en el mundo.

El artículo se desarrolla en tres secciones. En primer lugar, se presentan los conceptos más relevantes que están vinculados a las Relaciones Internacionales. En segundo lugar, se evidencia cómo los conceptos se pueden relacionar con el mundo de los cómics y la historia estelar, a partir de sus etapas a través del tiempo. Finalmente, se exponen algunos ejemplos narrativos que permiten evidenciar este suceso de manera más práctica.

\section{Diplomacia cultural}

La diplomacia cultural tiene una estrecha relación con el concepto de poder blando. A continuación, se presentan algunas definiciones que se retomaron para poder desarrollar ciertas precisiones y aproximaciones a este concepto, las cuales aportan autores como Joseph Nye (1990), Hans Morgenthau (1975) y Karl Deutsch (1974). De este modo, se pretende comprender el poder que tienen los elementos culturales en la sociedad.

Debido al énfasis de este estudio en los factores culturales, antes de desarrollar el concepto es importante reconocer la relevancia que tiene. De acuerdo con Montiel (2010, p. 5), "La cultura puede constituir un factor estratégico de primer orden, potencialmente el más influyente, por su versatilidad y plasticidad, pues actúa en los ámbitos del discernimiento y las conductas, allí donde se forjan las conciencias y las convicciones". Adicionalmente, como lo menciona Saddiki (2009), es necesario reconocer que la cultura se ha convertido en una herramienta importante para fomentar el entendimiento entre los países.

En este sentido, el lugar que la cultura ocupa dentro de la diplomacia de los estados ha cambiado considerablemente. Por consiguiente, su impacto en la conducción de esta y de la política exterior es incuestionable. La cultura se ha convertido tanto en una herramienta diplomática, en un puente indispensable para fomentar el entendimiento mutuo entre las naciones. Por lo tanto, cada vez más gobiernos le están concediendo una prioridad muy importante en su política exterior y en sus relaciones diplomáticas (Saddiki, 2009).

La diplomacia cultural está directamente relacionada con el concepto de poder blando (Soft Power), el cual fue introducido por Joseph Nye (1990), quien lo define como la habilidad para conseguir lo que uno pretende por medio de la seducción, y no por medio de la coerción o el 
pago. Entonces, surge del carácter atractivo que tienen la cultura, la política o los ideales políticos de un país.

Según Nye (1990), el poder blando que contempla un país tiene tres recursos principalmente: su cultura (en aquellas partes en que resulta atractiva a otros), sus valores políticos (cuando el país está a la altura de los mismos en casa y en el extranjero) y su política exterior (en el caso de ser considerada como legítima y con autoridad moral reconocida). Es evidente, entonces, que la cultura juega un papel muy importante en las relaciones exteriores de un país.

Por otro lado, Montiel (2010) menciona que el poder blando es la capacidad de atracción, propia al poder simbólico. Esta conduce, a menudo, a la aceptación de las posturas que intenta defender un país, sin que sea necesario recurrir a prebendas o a alguna forma de disuasión.

De otra manera, Hans Morgenthau (1975) ha resaltado la importancia que tiene la diplomacia sutil en el sistema internacional, el cual, según este autor, consiste en que "no tiene como objetivo la conquista de un territorio o el control de la vida económica de un país, sino la conquista y el control de las mentes de sus ciudadanos". Este concepto es muy relevante para efectos de la investigación, ya que, en el tercer apartado, se evidenciará como los cómics han llegado a tener el poder de persuadir la mente de las personas.

También se retoman los planteamientos de Karl Deutsch (1988 citado en Saddiki, 2009), quien menciona una premisa que establece un vínculo entre los intereses nacionales de un Estado y el lugar que desempeñan los factores culturales en su política exterior. Deutsch (citado en Saddiki, 2009, p. 110) observaba que "una cosa directamente vinculada a los intereses de cada Estado [...] es la política de difusión de su propia propaganda ideológica en los países extranjeros, y la política de apoyo a los intercambios científicos y culturales compatibles con este objetivo".
Adicionalmente, la diplomacia cultural tiene una estrecha relación con "los programas gubernamentalmente patrocinados cuyo objetivo es informar o influir en la opinión pública de otros países; sus instrumentos principales son publicaciones, películas, intercambios culturales, la radio y la televisión" (U.S. Department of State, 1987 citado en Saddiki, 2009, p. 109). Es decir, existe un fuerte vínculo entre la diplomacia cultural con la diplomacia pública.

Finalmente, es importante mencionar que algunos académicos consideran que "la diplomacia cultural, como una de las facetas de las relaciones internacionales, es uno de los aspectos 'blandos' de la convivencia en el planeta, frente a aspectos 'duros' como leyes y tratados, organizaciones multinacionales y capacidad militar" (Bound, Briggs, Holden y Jones, 2007, p.15).

\section{Objetivos de la diplomacia cultural}

La diplomacia cultural se desarrolla con el fin de promover la cultura y sus valores en otro país. Es decir, de cierta manera, busca lograr una imagen ante los demás. Por esta razón "el propósito fundamental de la diplomacia cultural es tender puentes que lleven al entendimiento mutuo a través de la expresión de su cultura, lengua, tradiciones y valores" (Rodríguez-Barba, 2015, p. 42). Los productos literarios y de entretenimiento, como los cómics, son instrumentos que permiten demostrar diferentes valores, tradiciones o costumbres de una cultura, reflejando lo que los creadores quieren transmitir sobre cierta cultural o cierta población específica.

También, es importante que el mensaje a transmitir sea de fácil entendimiento, es decir que las personas puedan percibir fácilmente dicho mensaje. Entonces "en efecto, un rasgo importante de la diplomacia cultural es la búsqueda del entendimiento recíproco a través de la expresión de los valores, las tradiciones y las manifestaciones artísticas y culturales" (Rodríguez-Barba, 2015, p. 42). 


\section{Otros enfoques y disciplinas}

Es importante resaltar la necesidad de la semiótica en este tipo de análisis, la cual se concibe como "la ciencia que estudia los sistemas de signos: lenguas, códigos, señalaciones" (Guiraud 1972, p. 9). Entonces, pueden analizarse ritos, ceremonias, expresiones del hombre y todo tipo de sistemas de comunicación que permitan el intercambio de información, que es, por definición, mediada por signos.

Como su centro de estudio recae en explicar a nivel estructural el procedimiento de comunicación y construcción de sentido, además de descifrar el significado latente de todo tipo de signos, esta disciplina "posibilita explicar tanto los fenómenos de la vida social ordinaria como los procesos por los cuales científicos, artistas, teólogos, brujos y chamanes, el hombre cotidiano, construyen cuerpos de conocimiento tendientes a dar al ser humano explicaciones sobre la existencia" (Toledo-Almada y Sequera-Meza, 2015, p. 11). En relación con la investigación,

El lenguaje de los cómics está formado por códigos lingüísticos, icónicos, cromáticos y gráficos. Mientras que el código lingüístico se interpreta como en cualquier otra narración, en el código icónico el cómic ha establecido una serie de convenciones propias, que le sirven para establecer significaciones profundas a través de una simple imagen (Cuñarro y Finol, 2013, p. 268)

Desde esta perspectiva, las narraciones son vistas en la Historia Estelar como "varias constelaciones que utilizan diversos puntos o estrellas de otras para generar su configuración de sentido o comprensión de la idea a través de la narrativa" (Ojeda-Pérez y Zapata, 2018, p. 529). A partir de lo anterior la semiótica puede ser usada como instrumento para entender imágenes, lo que estas representan y su trasfondo. En este trabajo la semiótica será entendida como:
La ciencia o disciplina que se interesa por el estudio de los diferentes tipos de símbolos creados por el ser humano en diferentes $y$ específicas situaciones. Este estudio se basa en el análisis de los significados que cada tipo de símbolo puede tener y cómo ese significado puede ir variando a lo largo del tiempo o del espacio. (Bembibre, 2010, p. 1)

Un poco de lo anterior se puede evidenciar, por ejemplo, en los colores de los trajes de los dos superhéroes analizados en el siguiente apartado, Nacionalismo, ya que en estos casos ambos poseen los colores casi exactos de la bandera de Estados Unidos.

\section{Nacionalismo}

El nacionalismo puede ser usado como ideología para establecer a una determinada nación como referente identitario de toda la humanidad y se puede decir que parte de dos de los conceptos básicos con respecto a la relación Nación-Estado. En primer lugar, la soberanía nacional: que mantendría la nación como la única base legítima para el estado. En segundo lugar, el Nacionalismo cuyo concepto es un poco más complejo y algunos autores como Snyder afirman que no tiene una definición exacta (Sociología en el Cómic, 2011).

El término nacionalismo no admite una simple definición, pues es un fenómeno complejo de carácter vago y misterioso. Su característica más permanente es que puede diferir en sus formas, de acuerdo con las condiciones históricas específicas y la estructura social de la sociedad. Entonces, puede tener un tinte cultural o, incluso, puede ser promovido como una excusa para la expansión (Snyder, 1954). Sin embargo, de acuerdo con Lawrence (2005 citado en Tirado, 2017, p. 16)

El nacionalismo puede referirse a una doctrina, un movimiento politico o un sentimiento. Como doctrina, el nacionalismo defiende que 
el mundo está dividido en una serie de comunidades humanas diferenciadas llamadas naciones y se preocupa de cómo definirlas. Como movimiento politico, el nacionalismo afirma que los intereses y valores de la nación tienen prioridad sobre todos los demás intereses y valores, siendo necesario que la misma sea lo más independiente posible, esto es, en último término, que las fronteras de la nación coincidan con las de un estado soberano. Como sentimiento, el nacionalismo sería la conciencia, mayoritariamente extendida dentro de una población, de pertenecer a un grupo determinado, identificable por un nombre y una historia y cultura compartidas.

Estados Unidos ha encontrado en los cómics una nueva forma de poder, no solo a través de la diplomacia cultural, sino, también, a partir del nacionalismo, ya que mediante este mecanismo ideológico ha logrado expandir aún más su hegemonía cultural. Esto dado que en el cómic la mayoría de sus personajes son arquetipos de lo que sería el buen americano, el patriota y el ciudadano ideal.

\section{La Historia Estelar}

La historia de los cómics puede analizarse desde la Historia Estelar en la medida en la que las historietas tienen su propia línea narrativa ficcional, la cual se inserta dentro de otra línea temporal de contexto. De este modo, se puede comparar con el universo en la medida que, en un sentido metafórico, está lleno de particularidades que, en su conjunto, forman un orden observado por el historiador, así como por el astrónomo. En la galaxia, en la vía láctea existe un centro estelar que ilumina los demás objetos y estos mismos reflejan sus iluminaciones, así es que se concibe el tiempo narrativo en la Historia Estelar, un reflejo del pasado hacia el presente, ocultado algunas veces por los astros o planetas que eclipsan su luz (Ojeda-Pérez y Zapata, 2018).
Un modelo que inspiró la creación de la Historia Estelar, como didáctica narrativa, fue el desarrollado por Hayden White(1992), quien analizó las principales formas de conciencia histórica del siglo XIX. Estas se basaban en el modelo de interpretación de White, en su libro Meta historia (1992). En este el autor propone estudiar las obras de maestros reconocidos de la historia y filósofos de la misma durante el siglo XIX. En el texto se encuentra el hilo conductor de la trama histórica, la cual permite identificar las narraciones de los cómics.

Desde esta perspectiva, White (1992) explica el pensamiento histórico a partir de un conjunto de estrategias: la explicación por la trama, por la argumentación formal y por implicación ideológica, así como la teoría de los tropos. Esto se puede comprender por medio de cinco niveles de conceptualización: la crónica, el relato, el modo de tramar, el modo de argumentación y el modo de implicación ideológica (White, 1992). Estos niveles de conceptualización son los que sirven para identificar la trama narrativa de los cómics. A continuación, se enfatiza en cada una de estos niveles, explicándolos con mayor profundidad, pues se considerarán en el desarrollo del ejercicio narrativo.

La narrativa de los cómics sigue una crónica y el relato lleva a cabo el proceso de selección y ordenamiento del registro de los hechos históricos. Puntualmente, la crónica tiene la función de conformar la estructura del relato. La explicación por trama es la que da el significado de un relato, mediante la identificación del tipo de relato que se ha narrado. Por su parte, el tramado "es la forma en que una secuencia determinada de sucesos que es organizada como un relato" (White, 1992, p. 19).

Se puede decir que el relato en la narrativa de los cómics tiene dos significados: puede ser histórico o de ficción. El primero hace referencia a hechos reales, propios de la literatura histórica. El segundo, el relato de ficción, es producto 
de la imaginación e invención del autor y está presente en la literatura de ficción, es decir, en la estructura narrativa del cómic bajo la trama.

Según Northrop Frye, en la Anatomía de la crítica literaria (1977), se identifican cuatro modos de llevar adelante la trama: el romance, la tragedia, la comedia y la sátira. El romance es un drama, cuya identificación está dada por la trascendencia de un héroe del mundo de la experiencia con una victoria final que produce su liberación de ese mundo (White, 1992). Por otra parte, la sátira se opone, justamente, al drama romántico de la redención. Volverse esclavo en un mundo en el que se creería señor. En cambio, la comedia y la tragedia suponen la posibilidad de liberación, aunque parcial, de la condición de la caída del hombre, con la eventualidad de un escape provisional de las condiciones en que el hombre vive en el mundo.

Según White(1992), "mientras que la comedia tiene una visión de la reconciliación final de fuerzas opuestas, la tragedia cae en una revelación de la naturaleza de las fuerzas que se oponen al hombre" (pp. 20-21).

En la argumentación formal se pueden evidenciar las operaciones racionales que realizan el historiador y el filósofo para apoyar su explicación en la narración. Stephen C. Pepper "distingue cuatro formas que pueden adoptar las explicaciones formales: formista, organicista, mecanicista y contextualista" (citado en White, 1992, p. 24). En este punto es necesario exponer en qué consiste cada una de dichas explicaciones formales:

- La teoría formista identifica las características exclusivas del campo histórico.

- La teoría organicista es integrativa de distintos aspectos o sucesos del campo histórico.
- La teoría mecanicista considera que cada caso se debe dar de forma reductiva, en la que cada acción o agente es visto como una fuerza supra histórica, que actúa como desarrollo de todos los acontecimientos.

- La teoría contextualista puede ser explicada a través de los sucesos, colocándolos en el contexto en el que ocurren.

En la explicación por implicación ideológica el autor propone distintas dimensiones en las que aborda el problema del conocimiento histórico. Karl Mannheim (citado en White, 1992) señala cuatro posiciones ideológicas: anarquismo, conservadurismo, radicalismo y liberalismo. En estas estrategias ideológicas la estética está dada por la trama, en la que actúa la estrategia argumental, la cual hace legible el discurso histórico.

Por otra parte, White (1992) tiene diferentes percepciones del tiempo, en las cuales han ocurrido varios cambios o trasformaciones sucedidos durante el siglo XIX. De este modo, se estudia el tiempo pasado y futuro, en cuestiones como el progreso y la decadencia. Como idea central el autor propone que la mayoría de las secuencias históricas pueden ser tramadas de distintas maneras, aportando diferentes interpretaciones y significados de los acontecimientos.

En este sentido, muchas veces en las narrativas en los héroes eclipsan el contexto del presente que están viviendo los países en torno a sus relaciones internacionales. Adicionalmente, en otras ocasiones, los contextos requieren de un mensaje o una interpretación que se puede establecer desde la misma historieta, por medio de la cual se fijan los mensajes más profundos de tipo político a sus interlocutores.

Entonces, las narrativas que se presentan en los cómics pueden evidenciar las distintas posturas que consideran las Relaciones Internacionales y la Historia, la cual puede ser considerada un modo de existencia, una conciencia histórica, un 
modo de pensamiento y un conocimiento histórico que ha dominado las ciencias físicas y humanas. Entonces, se puede decir que la conciencia histórica se fundamentó, principalmente, en la superioridad de la sociedad industrial moderna y se afirmó en la Guerra Fría.

Así, tanto en la obra histórica como en las narrativas de los cómics se presenta una estructura verbal en forma de discurso, de prosa narrativa, en la que el autor trata de identificar los componentes estructurales de sus relatos. Para poder comprender esas formas de conciencia y de representación histórica, su sentido y significado, son explicadas por el lenguaje poético y literario de los historiadores Michelet, Ranke, Tockeville, y Burkhardt, y filósofos como Hegel, Marx, Nietzsche y Croce (White, 1992).

\section{Cómics analizados}

Durante la Segunda Guerra Mundial en Estados Unidos fueron editados y publicados gran cantidad de tiras cómicas, las cuales, en sus caratulas y contenidos, mostraban al héroe con cierta personalidad y una postura fuertemente nacionalista. Además sus personajes principales se mostraban como Anti-Nazistas, enfrentándose a las fuerzas enemigas y resultando casi siempre victoriosos (Guaramato y Mendoza, s.f.).

Para el análisis que se presenta en este artículo se seleccionaron los cómics de El Capitán América y Superman, teniendo en cuenta que son dos de los referentes más importantes de este género y las épocas en las que sus primeros cómics surgieron, ya que ambos fueron creados en épocas importantes en la sociedad norteamericana "Superman en la Gran Depresión y Capitán América en la $2^{\circ}$ guerra mundial" (Sociología en el cómic, 2011, s.p.)

El Capitán América fue uno de los personajes clave para hacer propaganda a Estados Unidos durante la Segunda Guerra Mundial, ya que, a lo largo de toda su colección, representó a una
Norteamérica libre y democrática, que era atacada porque se oponía a una Europa (más específicamente Alemania) imperialista y guerrera. El Capitán América nació en el año 1941, cuando Estados Unidos estaba por declararle la guerra a Alemania. Su enemigo era Hitler, esto se puede evidenciar en la primera portada del superhéroe en 1941, cuyo inicio es un golpe a Adolf Hitler en la cara. A partir de allí Marvel seguiría desarrollando un discurso político que promovía el nacionalismo y denotaba una imagen negativa de Alemania y, principalmente, de Hitler, su líder (Del Rosario, 2016)

Superman, por otro lado, fue creado en 1938 por Jerry Siegel y Joe. Uno de los factores que influyó en las primeras historias y desarrollo del personaje fue el contexto de la Gran Depresión, época en la que Estados Unidos no solamente sufrió consecuencias económicas, sino, también, sociales (Sociología en el cómic, 2011). Desde su creación, el 'Hombre de Acero' fue un personaje familiar para la sociedad global, tanto en su lenguaje y sus expresiones historietístico como cinematográfico (Ravelo y Rodríguez-Ardanch, 2018).

El semiólogo y escritor italiano Umberto Eco en un famoso ensayo a finales de los sesenta ha permitido comprender, en parte, la idiosincrasia asociada a ese ideal comúnmente denominado "Americanidad", que se caracteriza por un conjunto de rasgos supuestamente inherentes a la cultura estadounidense: autosuficiencia, individualismo, independencia, utopismo, libertad, igualitarismo, oportunidad, democracia, anti-estatismo, populismo, conciencia de futuro y respeto por la ley. Estos valores, que provienen del puritanismo y del iluminismo europeo, forjaron la Declaración de la Independencia y la Constitución de los Estados Unidos de América (Ravelo y Rodríguez-Ardanch, 2018). Así,

En 1942, en plena Segunda Guerra Mundial, Superman se suma al odio contra el imperio nazi y sus creadores deciden enfrentarlo 
contra Hitler y las tropas japonesas, casi al mismo tiempo que el gobierno de los Estados Unidos decide ingresar activamente en el conflicto bélico (Ravelo y Rodríguez-Ardanch, 2018, p. 67).

Esto claramente demuestra gran similitud con la historia anteriormente mencionada sobre el Capitán América.

Además, si bien es cierto que durante la Segunda Guerra Mundial el cómic súper heroico fue utilizado para propagar una corriente de pensamiento nacionalista de forma explícita, también es evidente la idea de generar una supremacía americana, que combate el nacionalsocialismo, la cual es muy fácil de notar en una confrontación entre Superman y Hitler. Adicionalmente, hay viñetas o portadas de esa etapa que no responden a ese fin y que, en cambio, despliegan un relato costumbrista, pretendiendo reflejar la personalidad americana: Superman como un agente social que cuida a sus ciudadanos, asegurando el respeto por la verdad, el orden y la ley.

Por otro lado, con respecto a la guerra de Vietnam, los cómics de Superman no fueron explotados políticamente con tanta frecuencia. Aunque sí existieron excepciones en las que el Superhéroe ayudó a combatirlas (Ravelo y Rodríguez-Ardanch, 2018).

Concluida la Segunda Guerra Mundial, Superman regresó a sus aventuras netamente fantasiosas, entrando en un período mucho más simple en cuanto al contenido de sus historias, las cuales se extendieron hasta mediados de los ochenta. En estos años se perdió un poco su popularidad, igual que en el caso de Capitán América. Debido a esto los escritores empezaron a darles distintos giros a sus historias, añadiendo, esta vez, más drama a los personajes (Ravelo y Rodríguez-Ardanch, 2018).

En este sentido, se pueden identificar dos situaciones en las cuales Estados Unidos usa el cómic como una dinámica para manipular la realidad a su favor. Por un lado, el momento en el que el país cae en una crisis. En este instante la aparición de un superhéroe que dé algún modo representa la lucha contra esa crisis y, de este modo, Estados Unidos se muestra débil y derrotado frente a un enemigo que busca dañarlo para poder justificarse. Por otro lado, al momento de un ataque, Estados Unidos, por lo general, muestra al mundo su primera enmienda, que señala que USA no ataca sin ser agredido primero, por lo que identifica a un culpable y enemigo así poder embestirlo.

De estos acontecimientos surge alguna historia de cómic de superhéroe, que muestra al mundo por qué era necesario atacar y por qué está bien hacerlo, ya que, de este modo, están luchando por los ideales y la libertad o seguridad, no solo de sus ciudadanos, sino del mundo. A continuación, se evidencia lo que se ha mencionado en relación con las etapas del cómic, estableciendo vínculos con sus sucesos históricos y el ejemplo del ataque a las Torres Gemelas el 11 de septiembre del 2001.

\section{Etapas históricas de los cómics: oro, bronce $y$ moderna}

Durante los años 30 la Gran Depresión económica en Estados Unidos causó muchos estragos. No solo en materia económica, sino, también, en la mentalidad de sus ciudadanos. Es decir que los estadounidenses no estaban orgullosos de su modo de vida debido a tanta pobreza, por lo que esta sociedad no encontraba una identidad propia. Como consecuencia, el cambio de mentalidad de sus ciudadanos, quienes querían volver a la felicidad de los años 20, quedó en manos del expresidente Roosevelt.

A finales de los años 30, exactamente en el año 1939, hubo un auge en los libros de cómics, y con ello inició de la primera etapa de estos: $L a$ edad de oro. Los personajes más relevantes en 
esta etapa fueron Superman y Batman, ambos superhéroes creados por Jerry Siegel y Joe Shuster. Esto se sucedió mientras comenzaba la Segunda Guerra Mundial, "la guerra comenzó en 1939, como un conflicto exclusivamente europeo, y, en efecto, después de que Alemania invadiera Polonia, que en sólo tres semanas fue aplastada y repartida con la URSS" (Hobsbawm, 2010, p. 46).

Posteriormente, en 1940 Estados Unidos se encontraba al margen del conflicto de la Segunda Guerra Mundial, es decir, se mantenía sin ninguna participación, como consecuencia de la crisis económica y social que acababa de tener. el cual, según Castañeda-Lozano (2018), proyectaba en la congelación de los valores tradicionales del patriotismo, la libertad, la democracia y, en general, los de un auténtico liderazgo. En este personaje el patriotismo se evidenció en el uso del uniforme con los colores de la bandera de los Estados Unidos (Castañeda-Lozano, 2018). Es decir, fue un producto de inspiración patriótica.

Después de la Segunda Guerra Mundial las dos superpotencias, Estados Unidos y la URSS, tenían una disputa, pues pretendían expandir su doctrina ideológica y política propia en el resto del mundo. Es decir, había un escenario bipolar, pues el modelo que perseguía Estados Unidos era el capitalismo y la URSS el comunista.

Adicionalmente, en la época en 1941 se creó, también, la Mujer Maravilla, la cual, según Corrales (2014), era otro personaje ícono del patriotismo estadounidense. Diana Prince (su nombre 'de civil') trabajaba como enfermera del ejército y como superheroína combatía también a los nazis. Se recuerda y retoma, así, el conflicto latente entre Estados Unidos y Alemania.

${ }^{1}$ Si bien la guerra fría comenzó en 1947, se considera como una etapa particular en la historia de los cómics, ya que la creación de algunos superhéroes se da mientras esta se desarrollaba.

En este contexto se abrió paso la edad de plata, la cual comprendía desde finales de los años 50 hasta principios de los 60. Durante este período también se crearon varios personajes importantes en los cómics, los cuales surgieron en contextos históricos importantes como la guerra Irán-Irak, la de Vietnam y la de Corea, todas estas en el marco de la guerra fría ${ }^{1}$.

Lo que se percibía hasta el momento era que Estados Unidos buscaba siempre un enemigo, tanto para sus cómics como para sus relaciones internacionales. Así, durante la Segunda Guerra Mundial fueron los nazis y en la Guerra Fría los comunistas. En otras palabras,

En la Segunda Guerra Mundial, los superhéroes combatieron a los enemigos nazis, sin dejar espacio a dudas sobre quiénes eran los buenos y quiénes los malos. Después de 1945, durante los primeros 20 años de Guerra Fría, el mal era encarnado por comunistas. John $L$. Donovan citado en Corrales, 2014, s.p.)

Otro hecho histórico significativo relacionado con la creación de superhéroes fue la muerte del expresidente J. F. Kennedy, el 22 de noviembre en 1963. En septiembre de 1963 se creó un grupo de superhéroes llamado Los Vengadores (The Avengers), el cual estaba compuesto por Iron Man, Hulk, Thor y el hombre hormiga, quienes rescataron del olvido al Capitán América. Lo interesante sobre este grupo eran los motivos por los cuales decidía que el Capitán América volviera a tener protagonismo, pues fue precisamente el asesinato del presidente J. F. Kennedy.

Así, por ejemplo, Iron Man (Anthony Edward Stark, su nombre de civil) evidenciaba por medio de sus características y actuaciones el contexto histórico en el cual fue creado (Castañeda-Lozano, 2018). Este personaje fue creado en la década de los 60 con una postura anticomunista, la cual fue mutando y suavizándose con la intervención de EE.UU en la Guerra de Vietnam. De este modo se evidenciaba su fuerte 
relación con lo que estaba sucediendo alrededor del mundo en torno a las Relaciones Internacionales.

Finalmente, en la edad moderna, la cual inició en 1974, los personajes creados continuaron con el gusto por las armas militares. De modo que la guerra no finalizó en estas historias, aun cuando había finalizado el tiempo del conflicto. Entonces, continuaba el interés por crear personajes que protegieran o defendieran a Estados Unidos, de modo que podrían considerarse como patriotas modernos.

Un claro ejemplo de ello fue que, en 1979, Marvel lanzó la Máquina de Guerra (James Rhodes), un aliado de Iron Man que luchó en la guerra de Vietnam. Dos décadas después este personaje asumió la armadura del Iron Patriot para hacer frente al terrorismo, con los colores blanco, azul y rojo, y una estrella en el pecho, similar a la del Capitán América (Corrales, 2014).

Como se ha expuesto, la creación de algunos superhéroes sirvió como estrategia para que los ciudadanos estadounidenses volviesen a creer en su país después de la Gran Depresión. Según Hernández-Cano (2009), los cómics de superhéroes, en su capacidad para articular un discurso y generar significado, poseían un alto grado de complejidad que patrocinaba el patriotismo estadounidense.

Es evidente, entonces, que existe una relación entre el contexto histórico que se estuviese viviendo en cierto momento y la invención de algunos superhéroes. Si bien la creación de estos personajes no tenía ningún tinte político, es posible evidenciar que algunos superhéroes tenían mucha afinidad con el tema, pues "Algunos guionistas han utilizado la capacidad para la narración simbólica del poder propia del género como una vía legítima para reflexionar sobre situaciones políticas contemporáneas (Jameson, 1983[1981] citado en Hernández-Cano, 2009, p. 105).
Es así, que las narraciones de los comics pueden señalar por un lado la historia de las relaciones internacionales, como acontecimientos reales, así como también desarrollar una trama discursiva de ficción en la que se establece una postura ideológica, argumentativa que apela a las figuras literarias para entrar en la conciencia de los lectores, y apoyar plataformas políticas con intereses específicos. Los comics pueden entonces tener, varias líneas narrativas, una la de la ficción y otra evidente la de la historia, pero puede existir una tercera línea narrativa en el comic que apela a la conciencia histórica a esto se le ha denominado la Historia Estelar. (Ojeda-Pérez y Lizcano-Roa, 2015)

\section{Ejemplo: Ataque 9/11}

El 11 de septiembre del 2001 el mundo se conmocionó al ver en directo el ataque a las torres gemelas en la ciudad de Nueva York. Para algunos especialistas este representa el rechazo a la occidentalización de Estados Unidos por la falsa moral que le vendía al mundo y la caída del American way of live (Sánchez-Román, 2015).

Según Stiglitz (2008 citado en Sánchez-Román, 2015), a partir de las condiciones sociales de desconfianza que esto provocó, aquellos que no eran 'americanos' empezaron a ser considerados como un peligro para la seguridad de la nación, lo que dio espacio, entre otras cosas, a una estrategia de los medios de comunicación para instaurar un clima de terror en todo el mundo. El 20 se septiembre del 2001 el, entonces, presidente de los Estados Unidos George W. Bush inició la campaña War on Terror y su primer paso fue atacar Afganistán, guerra que ha sido una de las más largas y costosas de los últimos tiempos

Una guerra de esta magnitud no solo implicaba la intervención del país y el ataque físico, sino que convocaba a los medios de comunicación para mostrar a la gente por qué esa guerra era necesaria y que era justa, ya que se luchaba por el bien del pueblo y el propio, por el bien de toda la 
Humanidad. Por esto Bush avanzó a la próxima etapa, apelando a la cultura y los valores norteamericanos para impulsar su lucha. En este instante las industrias más poderosas de Hollywood se unieron a la declaración de guerra y retomaron la figura del superhéroe para propagar el mensaje. Así, esta se convirtió en una técnica de representación de la cultura dominante. Por este motivo puede afirmarse que las películas producidas a partir de entonces formaron parte del panorama mediático después de los eventos del 9/11 (Sánchez-Román, 2015).

Trasladar la guerra a la pantalla grande significó, entonces, entrar en el juego de las representaciones. El cine como mediador cultural podía y lograba establecer sistemas de representación identitaria, de modo que la imagen de la pantalla se convertía en la imagen del mundo. Así, la identidad surgió como táctica para situar a una determinada nación o comunidad en la parte más alta de la jerarquización cultural. De esta manera, las películas proporcionaban imaginarios sobre sí mismos y sobre los otros, representaciones que favorecían la construcción de estructuras dominantes en las que circulaban discursos de legitimación y poder (Sánchez-Román, 2015).

Los Justicieros de la Nación surgieron en este contexto con toda la fuerza e impulso, en pro de la protección de los ideales del American Way, reforzando desde el universo ficcionalizado el relato político expuesto. Así, los superhéroes influenciaron a la sociedad en cada crisis: desde su origen durante la Gran Depresión hasta su compromiso patriota durante la Segunda Guerra Mundial (Botello, s.f.).

Así, en las películas y comics de superhéroes, el gobierno estadounidense ha encontrado la mejor "arma" de poder blando para maniobrar una estrategia política que desde el entretenimiento y la distracción busca representar a un pueblo americano en riesgo, una sociedad atacada sencillamente por el hecho de ser democrática y por amparar la libertad. (Sánchez-Román, 2015).

\section{Análisis de cómics desde el contexto}

\section{Black Panther}

La historia de Black Panther se origina en la nación ficticia de Wakanda, un país pequeño ubicado en África ecuatorial, delimitado por las naciones de Sudán, Uganda, Kenia, Somalia y Etiopía, la cual es caracterizada en el cómic como el único país africano que nunca fue colonizado. Este pequeño país es protegido por T'Challa, quien es el personaje ficticio más rico del Universo Marvel y el primer héroe negro en la historia del cómic norteamericano. De este modo, nació para representar y empoderar a una minoría. Su primera aparición fue en Fantastic Four \#52 (1966).

Lo curioso del personaje y su manera de interpretarlo desde el contenido de este artículo no solo tiene que ver con su raza, sino, también, con el origen de su nombre, ya que, de acuerdo con Machado (2020), este se puede relacionar a dos posibles hechos:

- El primero con The Black Panther Party, la cual era una organización nacionalista afroamericana, socialista y revolucionaria activa en EE.UU durante los años 1966 y 1982. Su intención principal era crear grupos de protección en los vecindarios cuya población era mayoritaria o totalmente negra para defenderlos de los abusos de la policía.

- El segundo hecho está relacionado con un partido político, solo que este era un poco más pequeño que el anterior. Este se llamaba Lowndes County Freedom Organization, el cual, para hacer frente al partido oponente, eligió como símbolo una pantera negra, inspirándose en la escuela de afroamericanos más emblemática de la zona, la cual era denominada Clark College. 
Este es un pequeño esbozo de la manera como se puede iniciar un análisis del cómic teniendo en cuenta el contexto en el cual se desarrolla la historieta e interpretando la realidad de una comunidad específica en las Relaciones Internacionales. De esta manera, se pueden empezar a establecer las conexiones históricas que se han mencionado a lo largo del texto.

\section{Conclusiones}

La guerra dejó muchas consecuencias, tanto políticas como económicas y sociales. Además, dejó la creación de héroes importantes para el mundo del cómic a nivel mundial. Independientemente de las afinidades o características que contengan dichos personajes, la creación de estos trajo consigo aportes para la cultura. En este sentido, puede afirmarse que los héroes son herencia de la guerra. De este modo, se evidencia que las Relaciones Internacionales, como disciplina, han hecho grandes aportes teóricos que permiten analizar cómo funciona el sistema internacional. Dentro de estos pueden mencionarse aportes conceptuales como la diplomacia cultural y el poder blando, conceptos clave que se han trabajado a lo largo del artículo.

Como se evidenció a lo largo de esta investigación, los cómics fueron usados como artefacto en el que se utilizaron narrativas como discurso político de poder dentro de las Relaciones Internacionales con unos intereses específicos en cada momento histórico. Por lo tanto, estos superhéroes han sido utilizados como instrumentos que facilitan la exportación de valores de un país a otro, lo cual se considera, teóricamente, como diplomacia cultural. Los valores exportados hacia otros países se hacen por medio de discursos y prácticas que se pueden articular junto con las narrativas de los cómics. Uno de los discursos más evidentes en este proceso es el nacionalismo estadounidense por medio de sus superhéroes.

Así, Estados Unidos ha logrado imponerse como hegemonía, no solo política, sino, también, cultural, impartiendo sus ideales alrededor del mundo.
En este sentido, a partir de la investigación se evidencia que los cómics de superhéroes son instrumentos narrativos que permiten articular discursos que se acomodan a los intereses de las naciones, más específicamente de Estados Unidos. Dentro de las narrativas de los superhéroes se reflejan distintas capas temporales en las que se cuentan los hechos de los personajes y, al mismo tiempo, las líneas de los acontecimientos, las cuales están muy ligadas a la realidad tanto del pasado como del presente. Estos hechos pueden ser considerados como unos puntos en el universo, que ayudan a configurar un orden narrativo en el que se entretejen simbologías, ideologías y mensajes políticos directos para cada momento histórico. Por lo tanto, es importante tener en cuenta el análisis interpretativo desde la hermenéutica o desde la Historia Estelar, con el objetivo de comprender el universo de sentido que se vislumbra dentro de los diversos planos narrativos. 


\section{Referencias}

Bembibre, C. (2010, marzo). Definición de Semiótica. Definición ABC. https://www.definicionabc.com/comunicacion/semiotica.php

Bernasconi, A. y Salgueiro, F. (s.f). "Las Súper Identidades": El discurso político identitario en los cómics de la Editorial Marvel de los años 1940 a 1942. SCRIBD. Recuperado el 11 de enero de 2021 de https://es.scribd.com/document/377958161/Bernasconi-Salgueiro

Botello, G. (s.f.). ¡Oh, la humanidad! Las Torres Gemelas y la caída de los poderosos. Academia. edu. Recuperado el 11 de enero de 2021 de https://www.academia.edu/10341082/Superhéroes_y_el_discurso_11_S

Bound, K., Briggs, R., Holden, J. y Jones, S. (2007). Cultural Diplomacy. Demos.

Castañeda-Lozano, Y. (2018). Avengers Infinity War. Metáfora de las ciudadanías actuales. Tecné, Episteme y Didaxis: TED, (Extraordin). https://revistas.pedagogica.edu.co/index. $\mathrm{php/TED/article/view/8965}$

Corrales, G. (2014, marzo 26). Superhéroes en los cómics: Defensores de las barras y las estrellas. La nación. https://www.nacion.com/ $\mathrm{viva/cine/superheroes-en-los-comics-de-}$ fensores-de-las-barras-y-las-estrellas/IRMVK3BMAVD4ROGWC4IT35PD2E/story/

Cuñarro, L. y Finol, J. (2013). Semiótica del cómic : códigos y convenciones. Signa: Revista de la Asociación Española de Semiótica, 22. https:// doi.org/10.5944/signa.vol22.2013.6353

Del Rosario, L. (2016). El cómic y el poder. Una perspectiva antropológica. Boletín Millares Carlo, (32), 52-65. https://dialnet.unirioja.es/ servlet/articulo?codigo $=5977015$
Deutsch, K. (1974). Política y Gobierno. Fondo de Cultura Económica.

Guaramato, A. y Mendoza, D. (s.f.). Contexto Histórico. Capitán América. https://sites.google.com/site/capitanamericaad/home

Guiraud, P. (1972). La semiología. Siglo veintiuno editores.

Hernández-Cano, E. (2009). Nuevo Orden Mundial. Narraciones sobre el poder y superhéroes en el cómic mainstream estadounidense de Stormwatch a Black Summer (1996-2008). Extravío. Revista Electrónica de Literatura Comparada, 4, 104-121. https://core.ac.uk/ download/pdf/71012926.pdf

Hobsbawm, E. (2010). Historia del Siglo XX $\left(14^{\mathrm{a}}\right.$ ed.). Crítica - GRIJALBO MONDADORI. Utrabajo original publicado en 1994).

Machado, M. (s.f.). 5 cómics que nacieron a partir de conflictos mundiales buscando cambiar la realidad. Vix. https://www.vix.com/es/comics/179437/5-comics-que-nacieron-a-partir-de-conflictos-mundiales-buscando-cam$\underline{\text { biar-la-realidad }}$

Montiel, E. (2010). Diplomacia cultural. Un enfoque estrategico de Política Exterior para la era intercultural. En UNESCO (Ed.). Cultura \& vida. Un enfoque estrategico de Política Exterior para la era intercultural (pp. 5-24). UNSECO. https://silo.tips/download/cultura-vida-diplomacia-cultural-un-enfoque-estrategico-de-politica-exterior-par\#

Morgenthau, H. (1975). Politics Among Nations: The struggle for Power and Peace (5th ed). Alfred A. Knopft. 
Nye, J. (1990). Soft Power. Foreign Policy, (80), 153-171. https://doi.org/10.2307/1148580

Ojeda-Pérez, R. y Lizcano-Roa, J. P. (2015). Construcción de identidad desde las narraciones con una perspectiva psicohistórica. Aletheia, 7(2), 12-29. https://aletheia.cinde.org. co/index.php/ALETHEIA/article/view/252

Ojeda-Pérez, R. y Zapata, M. I. (2018). De la Historia antigua a la Historia Estelar, un viaje a través del tiempo. Revista Cambios y Permanencias, 9(2), 527-551. https://revistas. uis.edu.co/index.php/revistacyp/article/ view/9197

Ravelo, L. C. y Rodríguez-Ardanch, N. D. (2018). El mito de Superman. Algunas reflexiones sobre la conceptualización mitológica del superhéroe como brazo armado en conflictos bélicos (1939-2005). Revista luthor, 8(37), 60-77. https://www.academia. edu/41504052/Revista_Luthor_Nro_37 Agosto_2018_

Rodríguez-Barba, F. (2015). Diplomacia cultural. ¿Qué es y qué no es?. Espacios Públicos, 18(43),33-49. https://www.redalyc.org/articulo.oa?id $=676 / 67642415002$

Saddiki, S. (2009). El papel de la diplomacia cultural en las relaciones internacionales. Revista CIDOB D’Afers Internacionals, (88), 107-118. http://www.jstor.org/stable/40586505

Sánchez-Román, M. E. (2015). Superhéroes en la pantalla de la guerra contra el terror. Un estudio semiótico-discursivo a las trilogías cinematográficas Iron Man y The Dark Knight [Tesis doctoral, Universitat de Barcelona]. Repositorio Digital de la UB. https://apastyle.apa.org/ style-grammar-guidelines/references/examples/published-dissertation-references
Snyder, L. (1954). The Meaning of Nationalism. New Brunswick, Rutgers University Press.

Sociología en el cómic. (2011, mayo 21). Nacionalismo en el comic: Superman y Capitán América. Sociología en el cómic. http://sociologiacomic.blogspot.com/2011/05/nacionalismo-en-el-comic-superman-y_21.html

Tirado-Sarti, F. J. (2017). La evolución del concepto de Nación en la historia de los Estados Unidos (s. XIX) [Tesis doctoral, Universidad Complutense de Madrid]. E-Prints Complutense. https://eprints.ucm.es/id/eprint/42563/

Toledo-Almada, A. y Sequera-Meza, J. A. (2015). La Producción Del Sentido: Semiosis Social. Razón Y Palabra, 18(3_88), 521-536. https://www.revistarazonypalabra.org/index.php/ryp/article/view/301

White, H. (1992). Metahistoria: la imaginación histórica en el siglo diecinueve. Fondo de Cultura Económica. 